OPEN ACCESS

Edited by:

Jin Niu,

Sun Yat-sen University, China

Reviewed by:

Guangzhen Jiang,

Nanjing Agricultural University, China

Min Jin,

Ningbo University, China

*Correspondence:

Dong Han

hand21cn@ihb.ac.cn

${ }^{\dagger}$ These authors have contributed equally to this work and share first authorship

Specialty section:

This article was submitted to

Aquatic Physiology,

a section of the journal

Frontiers in Marine Science

Received: 26 August 2021 Accepted: 08 October 2021 Published: 12 November 2021

Citation:

Lu Q, Xi L, Liu Y, Gong Y, Su J, Han D, Yang $Y$, Jin J, Liu H, Zhu $X$ and Xie $S$ (2021) Effects of Dietary Inclusion of Clostridium autoethanogenum Protein on the Growth Performance and Liver Health of Largemouth Bass

(Micropterus salmoides).

Front. Mar. Sci. 8:764964. doi: 10.3389/fmars.2021.764964

\section{Effects of Dietary Inclusion of Clostridium autoethanogenum Protein on the Growth Performance and Liver Health of Largemouth Bass (Micropterus salmoides)}

\author{
Qisheng Lu ${ }^{1,2+}$, Longwei Xi ${ }^{1,2 \dagger}$, Yulong Liu 1,2, Yulong Gong ${ }^{1,2}$, Jingzhi Su ${ }^{1,2}$, Dong Han ${ }^{1,2,3 *}$, \\ Yunxia Yang ${ }^{1}$, Junyan Jin ${ }^{1}$, Haokun Liu ${ }^{1}$, Xiaoming Zhu ${ }^{1}$ and Shouqi Xie ${ }^{1,2,4}$ \\ ${ }^{1}$ State Key Laboratory of Freshwater Ecology and Biotechnology, Institute of Hydrobiology, Chinese Academy of Sciences \\ (CAS), Wuhan, China, ${ }^{2}$ College of Advanced Agricultural Sciences, University of Chinese Academy of Sciences, Beijing, \\ China, ${ }^{3}$ Hubei Engineering Research Center for Aquatic Animal Nutrition and Feed, Wuhan, China, ${ }^{4}$ The Innovative Academy \\ of Seed Design, Chinese Academy of Sciences (CAS), Wuhan, China
}

Clostridium autoethanogenum protein (CAP) is a novel protein source for aqua-feeds. The present study aimed to investigate the effects of dietary CAP on growth performance, immunity, and liver health status of juvenile largemouth bass (Micropterus salmoides). Four isonitrogenous and isolipid experimental diets were formulated to replace 0\% (D1, control), 25\% (D2), 50\% (D3), and 75\% (D4) of fish meal by CAP. Fish (15.05 $\pm 0.08 \mathrm{~g})$ were randomly fed one of four experimental diets for 8 weeks. The results showed that weight gain (WG), specific growth rate (SGR), feeding rate (FR), viscerosomatic index (VSI), and hepatosomatic index (HSI) of the D4 group were significantly lower than D1, D2, and D3 groups $(P<0.05)$. With the increase of substitution level, the total antioxidant capacity (T-AOC) of liver tissue was significantly decreased, while the plasma alkaline phosphatase (AKP) activity was significantly increased $(P<0.05)$. Plasma alanine aminotransferase (ALT) and aspartate aminotransferase (AST) levels were significantly higher in D3 and D4 groups than in D1 and D2 groups $(P<0.05)$. Replacing 50 or $75 \%$ fish meal by CAP significantly induced the transcription level of apoptosis-promoting genes (bcl-2-associated death protein [bad] and bcl-2-assoxicated $\times$ protein; bag [bax]), anti-apoptosis-related genes (tumor protein 53 [p53] and b-cell lymphoma-2 [bcl-2]), and the apoptotic Caenorhabditis elegans (C. elegans) death gene-3 like caspases (cysteineaspartic proteases-3 [caspase-3], cysteine-aspartic proteases-8 [caspase-8], cysteineaspartic proteases-9 [caspase-9], and cysteine-aspartic proteases-10 [caspase-10]) in liver, while suppressed the gene expression of the inflammatory factors [interleukin- $1 \beta$ (il-1 $\beta$ ), interleukin-8 (il-8), and tumor necrosis factor, thf] in head kidney. At the same time, dietary inclusion of CAP elevated the protein expression of bcl-2, autophagy microtubule-associated protein light chain 3A/B (LC3A/B-I), and LC3A/B-II by inhibiting the phosphorylation of the mammalian target of rapamycin (mTOR; $P<0.05$ ). Moreover, the apoptosis rate of the D3 and D4 groups was significantly increased $(P<0.05)$. Taken 
together, these results indicated that the optimal level of CAP-replacing fish meal should be $<50 \%$ that has no negative effect on the growth performance and liver health of juvenile largemouth bass. In addition, excessive CAP inclusion may damage liver health by activating autophagy and apoptosis signaling pathways.

Keywords: growth performance, liver health, apoptosis, largemouth bass, Clostridium autoethanogenum protein

\section{INTRODUCTION}

Fish meal is the preferred protein for aqua-feed because of its balanced nutrition and good palatability (Henry et al., 2015). With the rapid development of the aquaculture industry and the unsustainability of fish resources, an alternative protein source for fish meal is increasingly important (Hardy et al., 2018). Many research efforts have aimed to replace fish meal with soybean meal or other plant proteins (e.g., Kaushik et al., 1995; Sitjà-Bobadilla et al., 2005; Sahlmann et al., 2019), but disadvantages, such as imbalance of amino acid profile (Mambrini et al., 1999), anti-nutritional factors (Francis et al., 2001), and unpalatability (Luo et al., 2010), have limited the further application of plant proteins. In recent years, some new alternative proteins, such as single-cell protein (SCP), have attracted much attention because of the high efficiency and stability of the production and less anti-nutritional factors (Davies and Wareham, 1988).

Clostridium autoethanogenum protein (CAP) is a new type of bacterial protein produced by using Clostridium autoethanogenum (CA), which has no toxic genes (Utturkar et al., 2015). Meanwhile, the crude protein content of CAP is more than $72 \%$, which has a similar essential amino acid profile to fish meal, with considerable amounts of carbohydrate, lipid, and vitamin (Simpson et al., 2016). As a pretty novel SCP, current preliminary studies only evaluate the effects of the supplementation with CAP on the growth, digestion, and antioxidant capacity of grass carp (Ctenopharyngodon idella), (Wei et al., 2018), Jian carp (Cyprinus carpio var. Jian), (Li M. Y. et al., 2021), tilapia (GIFT: Oreochromis niloticus), (Maulu et al., 2020, 2021), and black sea bream (Acanthopagrus schlegelii), (Chen Y. et al., 2020), but few studies to date have focused on the liver health of fish and the regulation mechanism of dietary inclusion of CAP, especially in high inclusion levels.

Largemouth bass (Micropterus salmoides), a typical carnivorous fish, has become an important freshwater fish species in China, with a total cultured production of 477, 808 tons in 2019 (Fishery Bureau, 2020). In the past few years, researchers have devoted their energy to the effect of SCP on the growth of largemouth bass, such as yeast hydrolysate (Zhou et al., 2018; Gong et al., 2019) and symbiotic (Yang et al., 2020). CAP includes renewable energy, environmentally friendly ingredients, and has a high crude protein content. Therefore, the present study investigated four levels of CAP to replace fish meal to study their effects on growth performance and the way to affect liver health of largemouth bass, to provide a reference for the application of CAP in aquatic feed.

\section{MATERIALS AND METHODS Diet Preparation}

The formulation of the experimental diets was formulated in this study (Table 1). CAP was purchased from Hebei Shoulang New Energy Technology Co., Ltd., (Tangshan, Hebei, China). Four experimental diets were formulated to include $0,8.1,16.2$, and $24.3 \%$ of CAP replacing $0 \%(\mathrm{D} 1), 25 \%$ (D2), 50\% (D3), and 75\% (D4) of dietary fish meal, respectively. D1, where the fish meal content was $40 \%$ and was used as the control diet. All the diets were made in puffing feed, and the extruded diets were processed through an extruder (TSE65S; Modern Yanggong Machinery S\&T Development Co., Ltd. Beijing, China). All the wet diets were oven-dried at $60^{\circ} \mathrm{C}$ and stored at $-20^{\circ} \mathrm{C}$ until used.

\section{Fish and Trial Management}

Largemouth bass were purchased from a fish farm (Ezhou, Hubei, China). All fish were cultured in an experimental system with a D1 diet for 2 weeks to adapt to the rearing conditions. Before the trial, all fish have fasted $24 \mathrm{~h}$ for gastric emptying. Then, 24 similar-size largemouth bass (initial weight: $15.05 \pm$ $0.08 \mathrm{~g}$ ) were randomly selected, weighed, and put into each tank (volume: $200 \mathrm{~L}$ ). Three replicates were randomly distributed for one experimental diet. During the experiment, fish were fed to apparent satiation twice a day (08:30 and 16:30) and daily feed intake was recorded. Uneaten feed was taken out and recorded. The feeding trial lasted for 8 weeks. During the whole trial, the water temperature was kept at $26.0 \pm 1.0^{\circ} \mathrm{C}$. Water-dissolved oxygen content was maintained at $6.4 \pm 0.5 \mathrm{mg} / \mathrm{L}$, and ammonia$\mathrm{N}$ was lower than $0.5 \mathrm{mg} / \mathrm{L}$. The photoperiod was $12-\mathrm{h}$ light/12-h dark, with the light period from 08:00 to 20:00.

\section{Sample Collection}

Twenty-four hours after the last feeding, the fish in each experimental group were counted and batched weighed. Six fish per tank were randomly selected and anesthetized (MS222; Sigma, St Louis, MO, USA at $10 \mathrm{mg} \mathrm{L}^{-1}$ ) for sampling. Three fish in each tank were randomly used to measure the physical index. Three fish per tank were selected to collect blood samples from a caudal vein with heparinized syringes. Plasma was centrifuged $(3,000 \times \mathrm{g}$ for $10 \mathrm{~min})$ at $4^{\circ} \mathrm{C}$ and then the supernatant was collected, immediately frozen in liquid nitrogen, and stored at $-80^{\circ} \mathrm{C}$ for further analysis. Three fish per tank were chosen randomly, and liver and head kidney tissues were rapidly sampled, placed in liquid nitrogen, and stored at $-80^{\circ} \mathrm{C}$ for subsequent analysis. Two fish per tank were sampled for the analysis of terminal deoxynucleotidyl transferase dUTP nick end labeling (TUNEL). 
TABLE 1 | Formulation and proximate composition of the experimental diets.

\begin{tabular}{|c|c|c|c|c|}
\hline Ingredient (g/kg dry matter) & D1 & D2 & D3 & D4 \\
\hline Fishmeal $^{\mathrm{a}}$ & 400.0 & 300.0 & 200.0 & 100 \\
\hline Clostridium autoethanogenum protein ${ }^{b}$ & 0.0 & 81.0 & 162.0 & 243 \\
\hline Blood meal ${ }^{\mathrm{C}}$ & 40.0 & 40.0 & 40.0 & 40.0 \\
\hline Gluten $^{d}$ & 50.0 & 50.0 & 50.0 & 50 \\
\hline Soybean meal ${ }^{e}$ & 100.0 & 100.0 & 100.0 & 100 \\
\hline Soybean protein concentrate ${ }^{f}$ & 130.0 & 130.0 & 130.0 & 130. \\
\hline Cassava starch ${ }^{g}$ & 110.0 & 110.0 & 110.0 & 110 \\
\hline Fish oil & 35.0 & 38.8 & 42.5 & 46 \\
\hline Soybean oil & 35.0 & 38.8 & 42.5 & 46.2 \\
\hline Vitamin and mineral additives ${ }^{h}$ & 10.0 & 10.0 & 10.0 & 10.0 \\
\hline Monocalcium phosphate & 15.0 & 15.0 & 15.0 & 15.0 \\
\hline Choline chloride & 1.0 & 1.0 & 1.0 & 1.0 \\
\hline Microcrystalline cellulose & 74.0 & 85.4 & 97.0 & 108. \\
\hline \multicolumn{5}{|l|}{ Proximate composition } \\
\hline Crude protein & 499.3 & 495.5 & 500.6 & 505 \\
\hline Lipid & 90.9 & 82.6 & 88.2 & 86. \\
\hline
\end{tabular}

a Fishmeal: from Superprime, TASA Fish Product Co. Ltd, Peru. ${ }^{b}$ Clostridium autoethanogenum protein: from Hebei Shoulang New Energy Technology Co., Ltd. ${ }^{C}$ Blood meal: from Beijing Yangyuan Veterinary Medicine Technology Co., Ltd, Beijing, China. ${ }^{d}$ Gluten: from Henan Midaner Trading Co., Ltd, Xinzheng, Henan, China. ${ }^{e}$ Soybean meal: from Qingdao Bohai Agricultural Development Co., Ltd, Qingdao, China. ${ }^{f}$ Soybean protein concentrate: from Yihai grain and oil industry Co., Ltd, Taizhou, Jiangsu, China. ${ }^{9}$ Cassava starch: from Wuhan Yiteng Starch Co., Ltd, Wuhan, China. ${ }^{h}$ Vitamin and mineral additives: from Guangdong Nutriera Group, Guangzhou, China.

\section{Biochemical Analysis}

The activities of superoxide dismutase (SOD), glutathione peroxidase (GSH-Px), catalase (CAT), reduced glutathione (GSH), the content of malondialdehyde (MDA), and total antioxidant capacity (T-AOC) in the liver tissue were determined according to the instruction of the commercial kits. In addition, the plasma alanine aminotransferase (ALT), aspartate aminotransferase (AST), and alkaline phosphatase (AKP) were tested using commercial kits according to the instructions of the manufacturer. All the commercial kits were from Nanjing Jiancheng Bioengineering Institute (Nanjing, Jiangsu, China).

\section{RNA Extraction and Quantitative Real-Time PCR (qRT-PCR)}

Total RNAs of liver and head kidney tissues were extracted according to the instruction of TRIzol Reagent (Ambion, Life Technologies, Carlsbad, CA, USA). M-MLV First-Strand Synthesis Kit (Invitrogen, Shanghai, China) was used to obtain cDNA by reversing transcription of total RNA. Real-time PCR was carried out with LightCycle ${ }^{\circledR} 480$ II system using LightCycle 480 SYBR Green I Master Mix (Roche, Switzerland). The reactions of real-time PCR were based on that described by $\mathrm{Su}$ et al. (2017). In the present study, $18 \mathrm{~s}$ and beta-actin ( $\beta$ actin) were chosen as internal references for normalization. The primers used for qRT-PCR in largemouth bass were showed in Table 2. Each sample was run in duplicate, and the results were calculated with the means.
TABLE 2 | Real-time PCR primers sequences.

\begin{tabular}{|c|c|c|c|}
\hline Gene & Primers & Primer sequence & Sources \\
\hline$\beta$-actin & $\begin{array}{l}\text { F } \\
\text { (forward primer) } \\
\mathrm{R} \\
\text { (reverse primer) }\end{array}$ & $\begin{array}{l}\text { AAAGGGAAATCGTGCGTGAC } \\
\text { AAGGAAGGCTGGAAGAGGG }\end{array}$ & $\begin{array}{l}\text { Sun et al., } \\
2020\end{array}$ \\
\hline $18 \mathrm{~s}$ & FR & $\begin{array}{l}\text { CGGCTACCACATCCAAGGAA } \\
\text { CCTGTATTGTTATIIITCGTC } \\
\text { ACTACCT }\end{array}$ & $\begin{array}{l}\text { Sun et al., } \\
2020\end{array}$ \\
\hline$i l-1 \beta$ & FR & $\begin{array}{l}\text { CGTGACTGACAGCAAAAAGA } \\
\text { GG } \\
\text { GATGCCCAGAGCCACAGTTC }\end{array}$ & $\begin{array}{l}\text { Yu et al., } \\
2019\end{array}$ \\
\hline$i l-8$ & FR & $\begin{array}{l}\text { CGTTGAACAGACTGGGAGAGATG } \\
\text { AGTGGGATGGCTTCATTATCT } \\
\text { TGT }\end{array}$ & $\begin{array}{l}\text { Yu et al., } \\
2019\end{array}$ \\
\hline $\operatorname{tnf}$ & FR & $\begin{array}{l}\text { CTTCGTCTACAGCCAGGCAT } \\
\text { CG } \\
\text { ПTGGCACACCGACCTCACC }\end{array}$ & $\begin{array}{l}\text { Yu et al., } \\
2019\end{array}$ \\
\hline bad & F R & $\begin{array}{l}\text { CACATTCGGATGCCACTAT } \\
\text { TTCTGCTCTTCTGCGATTGA }\end{array}$ & $\begin{array}{l}\text { Yin et al., } \\
2020\end{array}$ \\
\hline bax & FR & $\begin{array}{l}\text { TCTTCACTCAGTCCCACAAA } \\
\text { ATACCCTCCCAGCCACC }\end{array}$ & $\begin{array}{l}\text { Yin et al., } \\
2020\end{array}$ \\
\hline bag & FR & $\begin{array}{l}\text { ATGACCCGAGACACGACAC } \\
\text { CATAACCTGGGCGAAGAAT }\end{array}$ & $\begin{array}{l}\text { Yin et al., } \\
2020\end{array}$ \\
\hline p53 & FR & $\begin{array}{l}\text { AGATTGAATGGTGGTGGG } \\
\text { GTTCTGGCGGACTGGA }\end{array}$ & $\begin{array}{l}\text { XM_03873 } \\
0857.1\end{array}$ \\
\hline$b c l-2$ & FR & $\begin{array}{l}\text { CCATCCACGACGAACCTG } \\
\text { GGCGTATCGCTGCTCAAACT }\end{array}$ & $\begin{array}{l}\text { Yin et al., } \\
2020\end{array}$ \\
\hline caspase-3 & FR & $\begin{array}{l}\text { GCTTCATTCGTCTGTGTTC } \\
\text { CGAAAAAGTGATGTGAGGTA }\end{array}$ & $\begin{array}{l}\text { Yu et al., } \\
2019\end{array}$ \\
\hline caspase-8 & FR & $\begin{array}{l}\text { GAGACAGACAGCAGACAACCA } \\
\text { TTCCATTTCAGCAAACACATC }\end{array}$ & $\begin{array}{l}\text { Yin et al., } \\
2020\end{array}$ \\
\hline caspase-9 & FR & $\begin{array}{l}\text { CTGGAATGCCTTCAGGAGACG } \\
\text { GG } \\
\text { GGGAGGGGCAAGACAACA } \\
\text { GGGTG }\end{array}$ & $\begin{array}{l}\text { Yin et al., } \\
2020\end{array}$ \\
\hline caspase-10 & FR & $\begin{array}{l}\text { CAAACCACTCACAGCGTCTAC } \\
\text { AT } \\
\text { TGGTTGGTTGAGGACAGAGAG } \\
\text { GG }\end{array}$ & $\begin{array}{l}\text { Yin et al., } \\
2020\end{array}$ \\
\hline
\end{tabular}

\section{Western Blot}

Liver tissues were cell lysed by RIPA lysis buffer (Beyotime Biotechnology, China) containing protease inhibitor cocktail and phosphatase inhibitor cocktail (Roche, Basel, Switzerland). Proteins $(40 \mathrm{mg})$ were separated on sodium dodecyl sulfatepolyacrylamide (SDS-PAGE) gels and then transferred to polyvinylidene fluoride (PVDF) membranes. The membranes were blocked for $1 \mathrm{~h}$ by using 5\% skimmed milk in TBST buffer $(20 \mathrm{mM}$ Tris $\mathrm{HCl}, 150 \mathrm{mM}$ sodium chloride, $0.1 \%$ Tween 20, $\mathrm{pH} 7.5$ ) and then were incubated overnight at $4^{\circ} \mathrm{C}$ by using the following specific primary antibodies: mammalian target of rapamycin phosphorylation (P-mTOR) Antibody (1:1,000, \#2,971; Cell signaling, Danvers, MA, USA), mammalian target of rapamycin (mTOR) Antibody (1:1,000, \#2,972; Cell signaling, Danvers, MA, USA), BCL-2 Antibody (1:1,000, ab32,124; Abcam), or autophagy microtubule-associated protein light chain 3A/B (LC3A/B) Antibody (1:1,000, \#12,741; Cell 
signaling, Danvers, MA, USA). After washing, membranes were incubated with a secondary antibody: glyceraldehyde-3phosphate dehydrogenase (GAPDH; 1:1,000, ab8,245; Abcam). Wherein, GAPDH was used as an internal reference protein. The bands were acquired by ImageQuant LAS 4000mini (GE Healthcare Life Sciences) and quantified using Image J software (National Institutes of Health).

\section{Histological Analysis in the Liver Tissue}

To observe the pathological changes of the liver tissue, the tissues were fixed into $4 \%$ paraformaldehyde and were embedded in paraffin and cut into $4 \mu \mathrm{m}$ sections. The method of TUNEL technique was adopted (Lu et al., 2019). The relative area (\%) of the apoptotic nucleus was calculated by Image-Pro Plus 6.0.

\section{Statistical Analysis}

All data are presented as mean $\pm \mathrm{SE}(n \geq 3)$, and one-way ANOVA was used to detect the significance of the differences between groups in SPSS 20 (SPSS Inc., Chicago, IL, USA) for windows. The significant difference level was considered $P<0.05$.

\section{RESULTS}

\section{Growth Performance and Morphometric Parameters}

The results of growth, feed utilization, and morphological indices of largemouth bass fed experimental diets were shown in Table 3. After 8-week feeding, there was no significant difference between group D2 and the control group D1 from the perspective of various growth indicators. However, weight gain (WG), specific growth rate (SGR), feeding rate (FR), and hepatosomatic index (HSI) of the D4 group were significantly lower than in D1, D2, and D3 groups $(P<0.05)$, while there were no significant differences of growth performance between the three groups $(P$ $>0.05$ ). Besides, the feed conversion ratio (FCR) of the D1 and $\mathrm{D} 2$ groups also was significantly higher than D3 and D4 groups $(P<0.05)$.

\section{Biochemical Parameters}

The non-specific immunity-related parameters of plasma in largemouth bass were presented in Figure 1. The content of AKP in plasma increased significantly with dietary CAP concentrations $(P<0.05)$. Plasma ALT and AST levels were significantly lower in the D1 and D2 groups than in D3 and D4 groups $(P<0.05)$, and there were no significant differences between D1 and D2 groups $(P>0.05)$.

\section{Anti-Oxidant-Related Parameters in the Liver Tissue}

Figure 2 showed the activities of anti-oxidant enzymes. At the end of the 8-week feeding trial, the effects of dietary CAP inclusion on the anti-oxidation were compared among D1, D2, D3, and D4 groups. When the replacement level of fishmeal was exceeded 25\%, the activities of T-AOC and SOD in the liver tissues were reduced significantly $(P<0.05)$. The activity of GSH-Px in liver tissues of group D2 was highest among all groups
TABLE 3 | The effects of dietary CAP inclusion on growth performance, feed utilization, and biometric parameters of juvenile largemouth bass.

\begin{tabular}{lcccc}
\hline & D1 & D2 & D3 & D4 \\
\hline IBW (g) & $15.03 \pm 0.07$ & $15.09 \pm 0.10$ & $14.97 \pm 0.08$ & $15.12 \pm 0.07$ \\
FBW (g) & $59.41 \pm 2.59^{\mathrm{b}}$ & $65.56 \pm 2.11^{\mathrm{b}}$ & $61.56 \pm 0.51^{\mathrm{b}}$ & $49.30 \pm 2.40^{\mathrm{a}}$ \\
WG (\%) & $297.54 \pm 23.61^{\mathrm{b}}$ & $330.14 \pm 13.12^{\mathrm{b}}$ & $297.52 \pm 2.18^{\mathrm{b}}$ & $219.57 \pm 23.52^{\mathrm{a}}$ \\
SGR (\%/d) & $2.45 \pm 0.08^{\mathrm{b}}$ & $2.62 \pm 0.05^{\mathrm{b}}$ & $2.52 \pm 0.01^{\mathrm{b}}$ & $2.11 \pm 0.10^{\mathrm{a}}$ \\
FCR & $0.76 \pm 0.03^{\mathrm{b}}$ & $0.73 \pm 0.03^{\mathrm{b}}$ & $0.89 \pm 0.02^{\mathrm{c}}$ & $0.58 \pm 0.06^{\mathrm{a}}$ \\
FR (\% & $1.57 \pm 0.08^{\mathrm{b}}$ & $1.57 \pm 0.09^{\mathrm{b}}$ & $1.84 \pm 0.04^{\mathrm{b}}$ & $1.07 \pm 0.15^{\mathrm{a}}$ \\
BW/d) & & & & \\
HSI (\%) & $2.60 \pm 0.20^{\mathrm{b}}$ & $2.46 \pm 0.14^{\mathrm{b}}$ & $2.49 \pm 0.19^{\mathrm{b}}$ & $1.72 \pm 0.21^{\mathrm{a}}$ \\
\hline
\end{tabular}

CAP, Clostridium autoethanogenum protein; initial body weight (IBW, g) = initial body weight/initial number of fish; final body weight (FBW, $g$ ) = final body weight/final number of fish; weight gain (WG, \%) $=100 \times$ (final body weight - initial body weight)/initial body weight; specific growth rate $(S G R, \% /$ day $)=100 \times($ Ln final individual weight Ln initial individual weight)/number of feeding days; Feed conversion ratio (FCR) $=$ feed consumed/weight gain; feeding rate (FR, \% BW/d) = dry weight of feed $\times 100 /[$ (initial body weight + final body weight)/2J/days; hepatosomatic index (HSI, \%) = (liver weight/body weight) $\times 100$. Values were presented as means \pm SEM $(n=3)$, and bars with different letters indicated significantly differences $(P<0.05)$.

$(P<0.05)$, but there were no significant differences among the other three groups $(P>0.05)$. The MDA content of groups D3 and D4 was significantly higher than group D1 and D2 $(P<0.05)$, while there were no significant differences between D1 and D2 groups. Meanwhile, no significant difference between CAT and GSH was found among all groups $(P>0.05)$.

\section{Gene Expression Related to Immunity in the Head Kidney Tissue}

To investigate the immune status of CAP inclusion in the body, the mRNA expression of related genes was performed and shown in Figure 3. Compared with the control group D1, the transcriptional expressions of major inflammatory factors of interleukin-1 $\beta$ (il-1 $\beta$ ), interleukin-8 (il-8), and tumor necrosis factor $(\operatorname{tnf})$ were significantly downregulated in head kidney tissues of D3 and D4 groups $(P<0.05)$, while there was no difference in the expression of $i l-1 \beta$ and $\operatorname{tnf}$ between D1 and D2 groups $(P>0.05)$.

\section{Transcriptional and Protein Expression of Apoptosis and Autophagy in the Liver Tissue}

Dietary inclusion of CAP had a significant effect on mRNA expression of apoptosis in the liver tissue of largemouth bass (Figures 4A-I). Results showed that the mRNA expressions of apoptosis-promoting genes ( $b c l$-2-associated death protein [bad] and bcl-2-assoxicated $x$ protein; bag [bax]) and antiapoptosis-related genes (tumor protein 53 [p53] and b-cell lymphoma-2 [bcl-2]) in D3 and D4 groups were significantly higher than D1 and D2 groups, while there is no significant difference between D1 and D2 groups $(P<0.05)$. Moreover, the apoptotic C. elegans death gene-3 like caspases (cysteine-aspartic proteases-3 [caspase-3], cysteine-aspartic proteases-8 [caspase-8], cysteine-aspartic proteases-9 [caspase-9], and cysteine-aspartic 




FIGURE 1 | Effects of dietary CAP inclusion on plasma AKP, ALT and AST in largemouth bass after an 8-week feeding trial. (A) AKP, alkaline phosphatase; (B) ALT, alanine aminotransferase; (C) AST, aspartate aminotransferase. Values were presented as means \pm SEM ( $n=3$ at least), and bars with different letters indicated significant differences $(P<0.05)$. CAP, Clostridium autoethanogenum protein.

proteases-10 [caspase-10]) had the same phenomenon. To further understand the effects of dietary CAP on apoptosis and autophagy of juvenile largemouth bass, the expression of related proteins was detected and shown in Figures 4J-N. Dietary CAP inclusion significantly inhibited TOR phosphorylation (P$\mathrm{mTOR} / \mathrm{mTOR})$ in largemouth bass $(P<0.05)$. Compared with the control group D1, the expressions of the apoptosis-related protein (bcl-2) and autophagy-related protein (LC3A/B-I and LC3A/B-II) were significantly induced in D3 and D4 groups $(P$ $<0.05)$.

\section{Histological Analysis}

The histologic results of liver tissues are shown in Figure 5A. Apoptosis was stimulated by the grade levels of CAP inclusion, as the apoptotic rate (Figure 5B) of D3 and D4 groups was significantly higher than other groups $(P<0.05)$, while there was no significant difference between D1 and D2 groups $(P>0.05)$.

\section{DISCUSSION}

Clostridium autoethanogenum protein, a kind of SCP, is a byproduct of ethanol production. In the production process, clean energy sources, such as ethanol and bacterial protein, are finally obtained through five processes of gas pretreatment, fermentation, distillation dehydration, bacterial separation, spray drying, and sewage treatment, and about 1,500 t of bacterial protein can be obtained for each $10,000 \mathrm{t}$ of ethanol production, thereby having great development potential. The utilization of CAP in aquatic feeds greatly promotes the conversion and reuse of industrial wastes and reduces the emission of harmful gases. However, as CAP belongs to microbial fermentation products, and CA has not yet entered the feed additive catalog of China, further research is needed to comprehensively evaluate the biological safety of CAP.

In the present study, compared with the control group, the CAP replacement fish meal level of 25 and 50\% groups had no significant effect on the growth performance (WG, SGR, FR, and HSI) of largemouth bass. This is similar to the study in grass carp that dietary CAP lower than $50 \mathrm{~g} / \mathrm{kg}$ has no negative effect on the growth performance of the fish (Wei et al., 2018). Similarly, In the pearl gentian grouper (oepinephelus

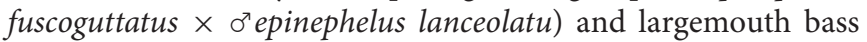
(Micropterus salmoides), cottonseed protein concentrate (CPC) could replace $24 \%$ fish meal, and a composite mixture of shrimp hydrolysate and plant proteins could take the place of $30 \%$ fish meal without affecting growth performance (Chen G. et al., 2020; Sla et al., 2020). This may be related to the fact that bacterial proteins are highly digestible and easy to use. However, when the level of CAP replacement fish meal exceeds 50\%, it will have a negative impact on the growth performance of largemouth bass. On the one hand, the content of lysine in CAP is low, and lysine has a great influence on the growth center (Chen Y. et al., 2020; Wang et al., 2020). Therefore, the relative lack of lysine content in feeds with high CAP replacement levels may cause the growth performance 

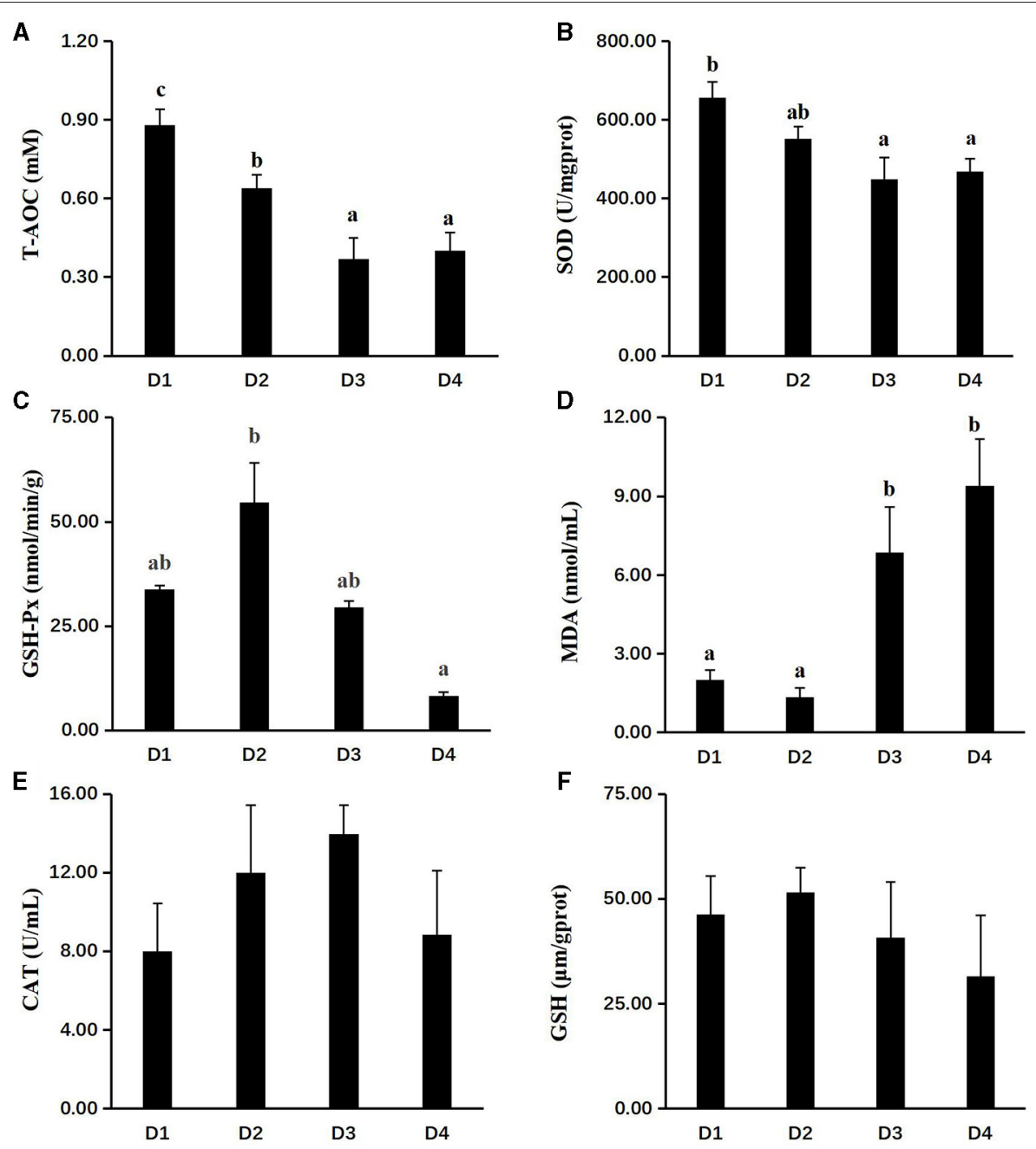

FIGURE 2 | Effects of dietary CAP inclusion on anti-oxidative capacity in liver. (A) T-AOC, total antioxidant capacity; (B) SOD, superoxide dismutase; (C) GSH-Px, glutathione peroxidase; (D) MAD, malondialdehyde; (E) CAT, catalase; and (F) GSH, reduced glutathione. Values were presented as means \pm SEM ( $n=3$ at least), and bars with different letters indicated significant differences $(P<0.05)$. CAP, Clostridium autoethanogenum protein.

of the D4 group to decline. On the other hand, palatability may be an important reason why CAP cannot completely replace fish meal. Similar results were reported in a study on rainbow trout (Oncorhynchus mykiss Walbaum), which is replacing fish meal with Methylobacterium extorquens SCP (Hardy et al., 2018). Therefore, according to the results of this experiment, the level of dietary CAP replacement fish meal should be $<50 \%$ and will not negatively affect the growth performance of largemouth bass. Importantly, the health status of fish may be a better explanation for the difference in growth performance.

Alanine aminotransferase, AST, and AKP are important indicators to measure liver health. Normal blood has relatively low contents of ALT, AST, and AKP. However, when the corresponding cells are damaged, the permeability of the cell membrane will be increased, and ALT, AST, and AKP in the cytoplasm will be released into the blood, resulting in an increase in blood contents, and suggesting extensive damage to the liver parenchyma. In the present study, ALT and AST in plasma were not significantly variational when the replacement of fishmeal was $25 \%$, compared with the control group D1, but their contents in plasma increased significantly after the fishmeal was replaced by more than $25 \%$. Similar results also appeared in other SCP substitution experiments (e.g., AbdelTawwab et al., 2010; Omar et al., 2012; Zhang et al., 2018). With the increase of substitution level, the plasma AKP content increased significantly. Anders and Stefan also found that in the experiment of feeding rainbow trout with bacterial protein instead of fish meal, excessive replacement may impair liver health (Anders and Stefan, 1993). These results implied that when the replacement amount of CAP exceeds 50\%, it may affect the liver health of largemouth bass.

Apoptosis, a marker of DNA fragmentation (Rhee et al., 2013), is a process in which cells end their lives voluntarily, 



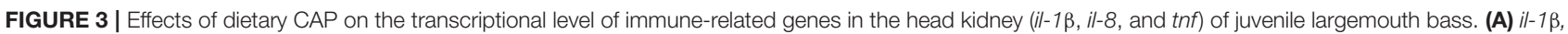
interleukin-1 $\beta$; (B) $i-8$, interleukin-8; and (C) thf, tumor necrosis factor. Values were presented as means \pm SEM ( $n=3$ at least), and bars with different letters indicated significantly differences $(P<0.05)$. CAP, Clostridium autoethanogenum protein.

and it is the basic to maintain cell homeostasis. Apoptosis can be activated by a variety of cellular signals, such as increased intracellular $\mathrm{Ca}^{2+}$ concentration, reactive oxygen species (ROS), such as hydroxyl radicals caused by oxidative damage (ROS), growth factors, and hormone stimulation caused by oxidative damage (Gump and Thorburn, 2011). As this study showed, juvenile largemouth bass fed with the D2 group did not have a significant effect on the level of apoptosis compared with the control group, while D3 and D4 groups had higher DNA fragmentation, supporting that high-level CAP could increase the level of apoptosis in largemouth bass. The induction effect of CAP on apoptosis may be correlated with the caspasedependent pathway. The caspase-dependent pathway is involved in the modulation of apoptosis (Ji et al., 2011). Among the caspases, caspase- 3 and caspase- 9 have been identified as a key executor of cell apoptosis (Li et al., 1997; Deng et al., 2009). In the cell apoptosis pathway which is independent of the death receptor, activated caspase- 9 initiated a protease cascade leading to the rapid activation of caspase-3 (Li et al., 1997). Moreover, the activation of the intrinsic apoptotic pathway leads to changes in gene expression, such as anti-apoptotic ( $b c l$ 2, bcl-xl, and bag) and pro-apoptotic factors (bax and bad), which respond to death signals (Breckenridge and Xue, 2004). Compared with D1 and D2 groups, significant upregulation in caspase- 3 and caspase- 9 mRNA expression was observed in D3 and D4 groups, respectively, which noted that excessive CAP replacement level could induce the upregulation of caspase3 and caspase-9 mRNA expressions. On the one hand, a significant positive correlation was observed between caspase- 9 mRNA level and the mRNA levels of caspase-3, caspase-8, and caspase-10, indicating that excessive CAP upregulated caspase- 9 mRNA expression partly through increasing caspase-3, caspase8 , and caspase-10 mRNA expressions. On the other, excessive protein replacement level of CAP can lead to increased mRNA expressions of pro-apoptotic ( $b a x$ and $b a d$ ) and anti-apoptotic (bcl-2, p53, and bag)-related factors. These results are consistent with research reported in Atlantic salmon (Salmo salar) that soybean meal activated caspase-3 and induced apoptosis (BakkeMcKellep et al., 2007). Autophagy, in a conservative way, at a basic level is necessary to maintain cell self-explanation and participate in the pathophysiological processes of the immune system and removal of micro-organisms, tumors, and other diseases (Jing and Lim, 2012; Ryter et al., 2014). At present, studies have found that mTOR inhibits autophagy and apoptosis ( $\mathrm{Li}$ L. et al., 2021). Besides, many classical apoptotic signaling pathways or proteins have been found to have complex interactions with the regulation of autophagy ( $\mathrm{Su}$ et al., 2013). Both LC3A/B-I and LC3A/B-II were considered molecular markers of autophagy in cells, and the content of LC3II was directly proportional to the degree of autophagy. It is worth pondering that CAP inhibits the mTOR signaling pathway and thus activates the autophagy and apoptosis pathway. It is possible that a high level of CAP substitutes for fish meal and lacks some essential amino acids, resulting in energy deficiency and activation of autophagy and apoptosis pathway (Liu et al., 2013). 


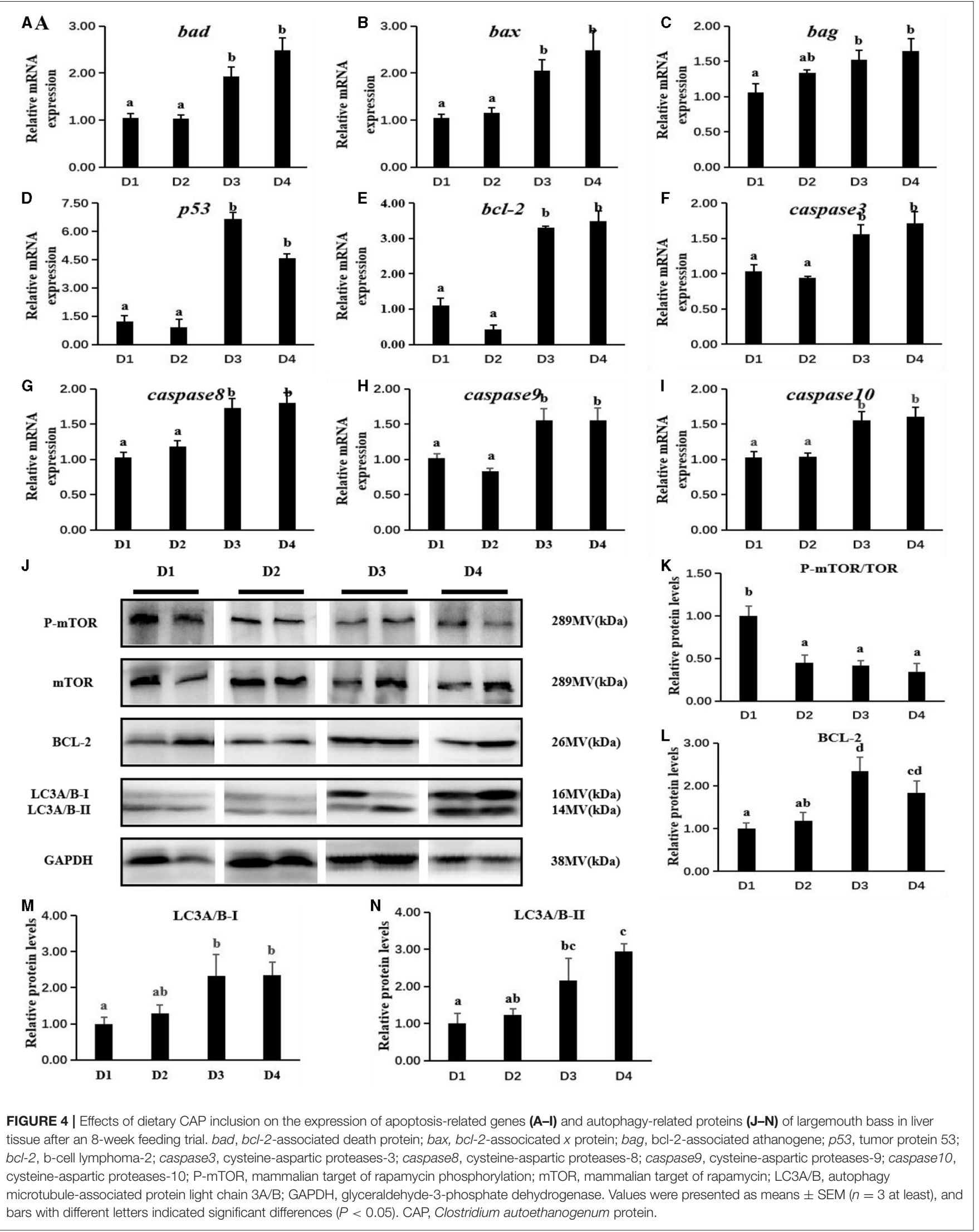


A
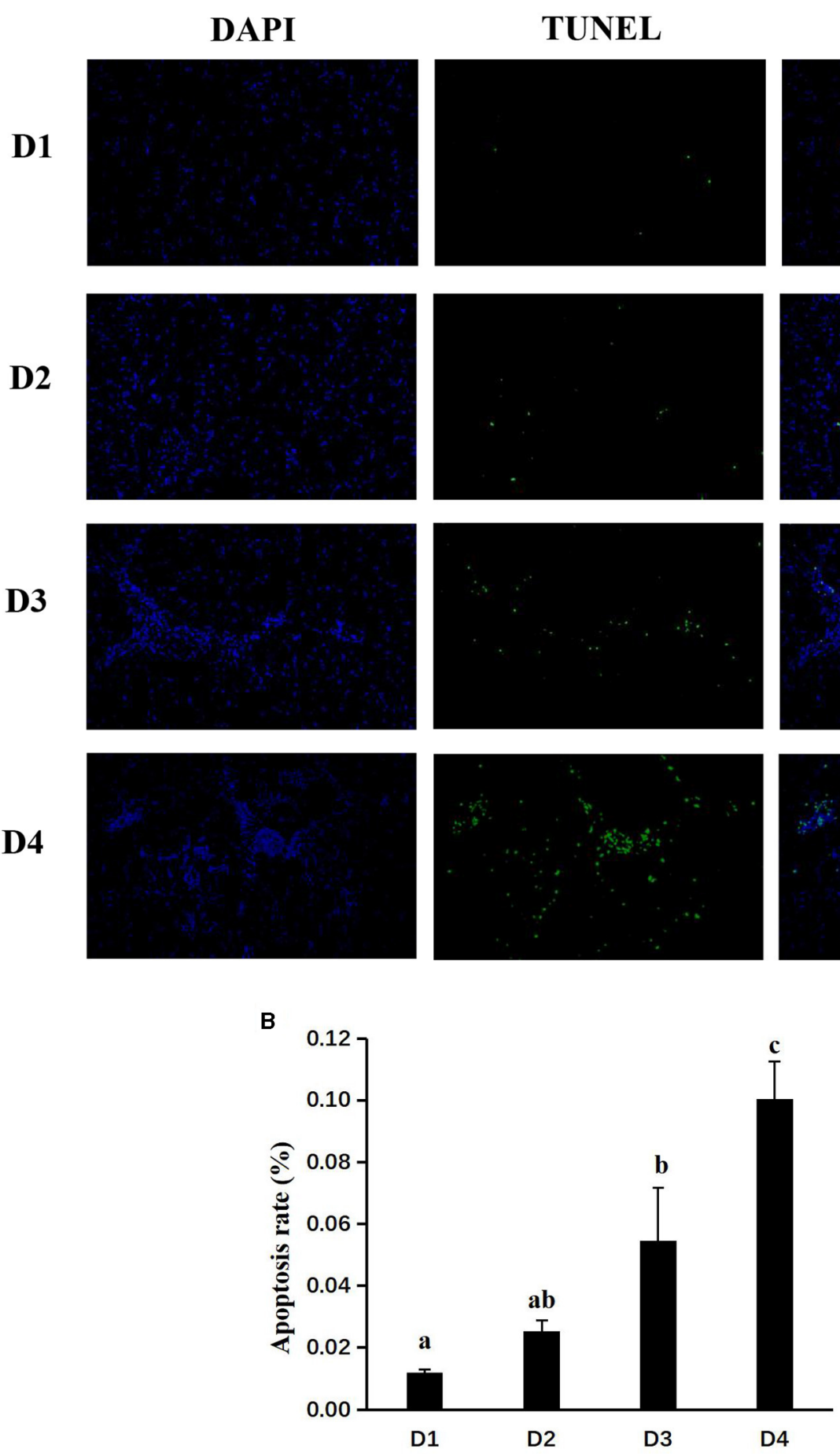

FIGURE 5 | Effects of dietary CAP inclusion on TUNEL (A) and apoptosis rate $\mathbf{( B )}$ in liver tissues of largemouth bass Values were presented as means \pm SEM $(n=3$ at least), and bars with different letters indicated significant differences $(P<0.05)$. CAP, Clostridium autoethanogenum protein; TUNEL, terminal deoxynucleotidyl transferase dUTP nick end labeling.

Most importantly, apoptosis and autophagy are consequences of exceeding ROS (Jin et al., 2011). Studies showed that elevated ROS levels caused oxidative damage in various organs, such as the liver tissue of fish (Jiang et al., 2011). The antioxidant enzyme system, consisting of SOD, GSH-Px, CAT, GSH, and T-AOC, is an antioxidant defense mechanism of the body 
that is closely related to health and can prevent the damage caused by reactive oxygen species and maintain the balance between the generation and removal of free radicals. When the oxidation-antioxidant balance tilts toward the oxidation direction, oxidative stress will occur and cause dysfunction and oxidative damage (Zeng et al., 2017). In the present experiment, it was found that the increased substitution level of CAP did not cause changes in the liver tissue of CAT and GSH activity. This is similar to the previous study that yeast culture has no effect on the antioxidant capacity of gibel carp (Carassius auratus gibelio CAS III), (Zhang et al., 2018). However, it caused a significant decrease in T-AOC, a comprehensive indicator of antioxidant activity. MDA, the final product of lipid peroxidation, is usually used to evaluate the health of the body (Fujioka and Shibamoto, 2005) and measure endogenous oxidative damage (Ding et al., 2015). When CAP substitutes for fishmeal at $25 \%$, there was no difference between the MDA content in the liver compared with the control group D1, but when it exceeded 25\%, the MDA content in the liver increased significantly. It showed that high levels of CAP substitution affected the antioxidant capacity of juvenile largemouth bass, leading to the accumulation of free radicals, which damaged liver health. Inversely, replacing fish meal with CAP in feed for juvenile black sea bream did not affect the antioxidant capacity of the liver tissue (Chen Y. et al., 2020). This conflicting result may be due to different fish and protein-processing methods used, which may have an impact on the availability and digestibility of nutrients.

As we all know, autophagy and apoptosis also belong to the category of immune homeostasis. Apoptosis is a programmed cell death that occurs cell-autonomously. The most important feature of immune autophagy is the capture and degradation of intracellular microorganisms by autophagy (Faure and Lafont, 2013). Autophagy occurs inside of cells, mainly to clean up the internal environment of cells. When the body is damaged by microbial adaptation mechanisms, autophagy can easily capture the pathogenic microorganisms invading cells through the autophagic aptamers known as sequestosome 1/p62 sample receptors (slr), (Deretic, 2012). Slr is involved in the release of pro-inflammatory factor signals through the thf receptorassociated factor or by activating caspase- 8 to promote cell death. Common pro-inflammatory factors are $i l-1 \beta, i l-8$, and tnf, which are also markers of inflammation and participate in host defense against microbial pathogens (Secombes et al., 2001; Corripio-Miyar et al., 2007). Il-1 $\beta$ signal initiates the production and secretion of pro-inflammatory mediators, such as $i l-8$, which can respond to inflammatory stimuli through several cell types. An exception is il-8 expression, which has been reported to affect the tnf expression (Giraudo et al., 1998). Notably, studies have shown that autophagy is related to the activation of inflammatory factors (Shi et al., 2012). In the present study, the head kidney il-1 $\beta$, il-8, and tnf expressions were downregulated in the CAP substitution groups D3 and D4. Similarly, dietary supplementation of $25 \%$ yeast had significantly downregulated the expression of $i l-1 \beta$ and $i l-8$ in the Atlantic salmon (Salmo salar), (Sahlmann et al., 2019). Il-1 $\beta$ promotes rapid response to infection by inducing a cascade of reactions leading to inflammation. These results indicated that more than $50 \%$ replacement of fish meal by CAP in the diet might result in decreased immunity of largemouth bass, which was consistent with the above results in the present study.

\section{CONCLUSIONS}

In conclusion, the present results indicated that replacing $<50 \%$ of dietary fish meal by CAP had no negative effects on growth performance, anti-oxidation capacity, immune response, autophagy, and apoptosis system of largemouth bass. However, excessive substitution by CAP may damage liver health by inhibiting mTOR phosphorylation to activate the autophagy and apoptosis pathways. Together, the utilization of CAP in aquafeeds will promote the conversion and reuse of industrial waste, reduce the emission of harmful gases, and has a huge potentiality.

\section{DATA AVAILABILITY STATEMENT}

The original contributions presented in the study are included in the article/supplementary materials, further inquiries can be directed to the corresponding author/s.

\section{ETHICS STATEMENT}

The animal study was reviewed and approved by the Institute of Hydrobiology, Chinese Academy of Science.

\section{AUTHOR CONTRIBUTIONS}

$\mathrm{DH}$ designed the experiment and revised the manuscript. QL and LX performed the experiment and drafted the manuscript. YL, JS, and HL performed the statistical analysis. YY contributed to the sample analysis. JJ, HL, XZ, and SX provided suggestions on the experimental design and contributed to the manuscript modification. All authors contributed to the article and approved the submitted version.

\section{FUNDING}

This work was funded by the National Key R\&D Program of China (2018YFD0900400 and 2019YFD0900200), China Agriculture Research System (CARS-46), the National Natural Science Foundation of China (31672670, 31972771, and 31972805), the Southern Marine Science and Engineering Guangdong Laboratory (Zhanjiang), (ZJW-2019-06), Fund Project in State Key Laboratory of Freshwater Ecology and Biotechnology (2019FBZ02 and 2019FBZ05), Hubei High-tech Innovation and Business Incubation Center (2019-02-055), and Science and Technology Project of Wuhan (2019020701011459).

\section{ACKNOWLEDGMENTS}

The authors thank Guanghan Nie for technical support with the research system. 


\section{REFERENCES}

Abdel-Tawwab, M., Mousa, A. A., and Mohammed, M. A. (2010). Use of live baker's yeast, Saccharomyces cerevisiae, in practical diet to enhance the growth performance of galilee tilapia, Sarotherodon galilaeus (L.), and its resistance to environmental copper toxicity. J. World Aquac. Soc. 41, 214-223. doi: 10.1111/j.1749-7345.2010.00361.x

Anders, K., and Stefan, A. (1993). Nutritive value of two bacterial strains of single-cell protein for rainbow trout (Oncorhynchus mykiss). Aquaculture 109, 119-130. doi: 10.1016/0044-8486(93)90209-H

Bakke-McKellep, A. M., Penn, M. H., Salas, P. M., Refstie, S., Sperstad, S., Landsverk, T., et al. (2007). Effects of dietary soyabean meal, inulin and oxytetracycline on intestinal microbiota and epithelial cell stress, apoptosis and proliferation in the teleost Atlantic salmon (Salmo salar L.). Br. J. Nutr. 97, 699-713. doi: 10.1017/S0007114507381397

Breckenridge, D. G., and Xue, D. (2004). Regulation of mitochondrial membrane permeabilization by BCL-2 family proteins and caspases. Curr. Opin. Cell Biol. 16, 647-652. doi: 10.1016/j.ceb.2004.09.009

Chen, G., Yin, B., Liu, H., Tan, B., Dong, X., Yang, Q., et al. (2020). Effects of fishmeal replacement with cottonseed protein concentrate on growth, digestive proteinase, intestinal morphology and microflora in pearl gentian

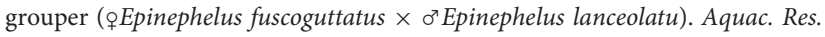
51, 2870-2884. doi: 10.1111/are.14626

Chen, Y., Sagada, G., Xu, B., Chao, W., Zou, F., Ng, W., et al. (2020). Partial replacement of fishmeal with clostridium autoethanogenum single-cell protein in the diet for juvenile black sea bream (acanthopagrus schlegelii). Aquac. Res. 51, 1000-1011. doi: 10.1111/are.14446

Corripio-Miyar, Y., Bird, S., Tsamopoulos, K., and Secombes, C. J. (2007). Cloning and expression analysis of two pro-inflammatory cytokines, IL-1 beta and IL-8, in haddock (Melanogrammus aeglefinus). Mol. Immunol. 44, 1361-1373. doi: $10.1016 /$ j.molimm.2006.05.010

Davies, S. J., and Wareham, H. (1988). A preliminary evaluation of an industrial single cell protein in practical diets for tilapia (Oreochromis mossambicus peters). Aquaculture 73, 189-199. doi: 10.1016/0044-8486(88)90053-1

Deng, J., Yu, L., Liu, C., Yu, K., and Zhou, B. (2009). Hexbromocyclododecaneinduced developmental toxicity and apoptosis in zebra fish embryos. Aquat. Toxicol. 93, 29-36. doi: 10.1016/j.aquatox.2009.03.001

Deretic, V. (2012). Autophagy as an innate immunity paradigm: expanding the scope and repertoire of pattern recognition receptors. Curr. Opin. Immunol. 24, 21-31. doi: 10.1016/j.coi.2011.10.006

Ding, Z., Zhang, Y., Ye, J., Du, Z., and Kong, Y. (2015). An evaluation of replacing fish meal with fermented soybean meal in the diet of Macrobrachium nipponense: growth, non-specific immunity, and resistance to Aeromonas hydrophila. Fish Shellfish Immunol. 44, 295-301. doi: 10.1016/j.fsi.2015.02.024

Faure, M., and Lafont, F. (2013). Pathogen-induced autophagy signaling in innate immunity. J. Innate Immun. 5, 456-470. doi: 10.1159/000350918

Fishery Bureau (2020). China Fishery Statistical Yearbook 2020. Beijing: China Agriculture Press.

Francis, G., Makkar, H., and Becker, K. (2001). Antinutritional factors present in plant-derived alternate fish feed ingredients and their effects in fish. Aquaculture 199, 197-227. doi: 10.1016/S0044-8486(01)00526-9

Fujioka, K., and Shibamoto, T. (2005). Improved malonaldehyde assay using headspace solid-phase microextraction and its application to the measurement of the antioxidant activity of phytochemicals. J. Agric. Food Chem. 53, 4708-4713. doi: 10.1021/jf050297q

Giraudo, E., Primo, L., Audero, E., Gerber, H. P., Koolwijk, P., Soker, S., et al. (1998). Tumor necrosis factor-alpha regulates expression of vascular endothelial growth factor receptor-2 and of its co-receptor neuropilin1 in human vascular endothelial cells. J. Biol. Chem. 273, 22128-22135. doi: $10.1074 / j b c .273 .34 .22128$

Gong, Y. L., Yang, F., Hu, J. P., Liu, C., Liu, H. K., Han, D., et al. (2019). Effects of dietary yeast hydrolysate on the growth, antioxidant response, immune response and disease resistance of largemouth bass (Micropterus salmoides). Fish Shellfish Immunol. 94, 548-557. doi: 10.1016/j.fsi.2019.09.044

Gump, J. M., and Thorburn, A. (2011). Autophagy and apoptosis: what is the connection? Trends Cell Biol. 21, 387-392. doi: 10.1016/j.tcb.2011.03.007
Hardy, R. W., Patro, B., Pujol-Baxley, C., Marx, C. J., and Feinberg, L. (2018). Partial replacement of soybean meal with Methylobacterium extorquens singlecell protein in feeds for rainbow trout (Oncorhynchus mykiss walbaum). Aquac. Res. 49, 2218-2224. doi: 10.1111/are.13678

Henry, M., Gasco, L., Piccolo, G., and Fountoulaki, E. (2015). Review on the use of insects in the diet of farmed fish: past and future. Anim. Feed Sci. Technol. 203, 1-22. doi: 10.1016/j.anifeedsci.2015.03.001

Ji, H., Li, J., and Liu, P. (2011). Regulation of growth performance and lipid metabolism by dietary $n-3$ highly unsaturated fatty acids in juvenile grass carp, Ctenopharyngodon idellus. Comp. Biochem. Physiol. B.. Biochem. Mol. Biol. 159, 49-56. doi: 10.1016/j.cbpb.2011.01.009

Jiang, W. D., Wu, P., Kuang, S. Y., Liu, Y., Jiang, J., Hu, K., et al. (2011). Myo-inositol prevents copper-induced oxidative damage and changes in antioxidant capacity in various organs and the enterocytes of juvenile Jian carp (cyprinus carpio var. jian). Aquat. Toxicol. 105, 543-551. doi: 10.1016/j.aquatox.2011.08.012

Jin, Y. X., Zheng, S. S., Pu, Y., Shu, L. J., Sun, L. W., Liu, W. P., et al. (2011). Cypermethrin has the potential to induce hepatic oxidative stress, DNA damage and apoptosis in adult zebrafish (Danio rerio). Chemosphere 82, 398-404. doi: 10.1016/j.chemosphere.2010.09.072

Jing, K., and Lim, K. (2012). Why is autophagy important in human diseases? Exp. Mol. Med. 44, 69-72. doi: 10.3858/emm.2012.44.2.028

Kaushik, S. J., Cravedi, J. P., Lalles, J. P., Sumpter, J., Fauconneau, B., and Laroche, M. (1995). Partial or total replacement of fish meal by soybean protein on growth, protein utilization, potential estrogenic or antigenic effects, cholesterolemia and flesh quality in rainbow trout, Oncorhynchus mykiss. Aquaculture 133, 257-274. doi: 10.1016/0044-8486(94)00403-B

Li, L., Wang, J., Feng, L., Fan, J. T., Wang, J., Tan, N. H., et al. (2021). Rubioncolin $C$, a natural naphthohydroquinone dimer isolated from Rubia yunnanensis, inhibits the proliferation and metastasis by inducing ROSmediated apoptotic and autophagic cell death in triple-negative breast cancer cells. J. Ethnopharmacol. 277:114184. doi: 10.1016/j.jep.2021.114184

Li, M. Y., Liang, H. L., Xie, J., Chao, W., Zhou, F. Q., Ge, X. P., et al. (2021). Diet supplemented with a novel Clostridium autoethanogenum protein have a positive effect on the growth performance, antioxidant status and immunity in juvenile Jian carp (Cyprinus carpio var. Jian). Aquac. Rep. 19:100572. doi: $10.1016 /$ j.aqrep.2020.100572

Li, P., Nijhawan, D., Budihardjo, I., Srinivasula, S. M., Ahmad, M., Alnemri, E. S., et al. (1997). Cytochrome c and dATP-dependent formation of Apaf1/caspase-9 complex initiates an apoptotic protease cascade. Cell 91, 479-489. doi: 10.1016/S0092-8674(00)80434-1

Liu, G., Bi, Y., Wang, R., and Wang, X. (2013). Self-eating and self-defense: autophagy controls innate immunity and adaptive immunity. J. Leukoc. Biol. 93, 511-519. doi: 10.1189/jlb.0812389

Lu, D. L., Ma, Q., Wang, J., Li, L. Y., Han, S. L., Limbu, S. M., et al. (2019). Fasting enhances cold resistance in fish through stimulating lipid catabolism and autophagy. J. Physiol. 597, 1585-1603. 13/JP277091 doi: 10.1113/JP277091

Luo, L., Xue, M., Wu, X. F., Cai, X. F., and Liang, Y. M. (2010). Partial or total replacement of fishmeal by solvent-extracted cottonseed meal in diets for juvenile rainbow trout (Oncorhynchus mykiss). Aquac. Nutr. 12, 418-424. doi: 10.1111/j.1365-2095.2006.00443.x

Mambrini, M., Roem, A. J., Carvèdi, J. P., Lallès, J. P., and Kaushik, S. J. (1999). Effects of replacing fish meal with soy protein concentrate and of DLmethionine supplementation in high-energy, extruded diets on the growth and nutrient utilization of rainbow trout, Oncorhynchus mykiss. J. Anim. Sci. 77, 2990-2999. doi: 10.2527/1999.77112990x

Maulu, S., Liang, H. L., Ge, X. P., Yu, H., Huang, D. Y., and Ke, J. (2021). Effect of dietary Clostridium autoethanogenum protein on growth, body composition, plasma parameters and hepatic genes expression related to growth and AMPK/TOR/PI3K signaling pathway of the genetically improved farmed tilapia (GIFT: Oreochromis niloticus) juveniles. Anim. Feed Sci. Technol. 276:114914. doi: 10.1016/j.anifeedsci.2021.114914

Maulu, S., Liang, H. L., Ke, J., Ren, M. C., Ge, X. P., Huang, D. Y., et al. (2020). Dietary Clostridium autoethanogenum protein modulates intestinal absorption, antioxidant status, and immune response in GIFT (Oreochromis niloticus) juveniles. Aquac. Res. 52, 5787-5799. doi: 10.1111/are.15454 
Omar, S. S., Merrifield, D. L., Kühlwein, H., Williams, P., and Davies, S. J. (2012). Biofuel derived yeast protein concentrate (YPC) as a novel feed ingredient in carp diets. Aquaculture 330-333, 54-62. doi: 10.1016/j.aquaculture.2011.12.004

Rhee, J. S., Yu, I. T., Kim, B. M., Jeong, C. B., Lee, K. W., Kim, M. J., et al. (2013). Copper induces apoptotic cell death through reactive oxygen species-triggered oxidative stress in the intertidal copepod Tigriopus japonicus. Aquat. Toxicol. 132-133, 182-189. doi: 10.1016/j.aquatox.2013.02.013

Ryter, S. W., Mizumura, K., and Choi, A. M. (2014). The impact of autophagy on cell death modalities. Int. J. Cell Biol. 2014:502676. doi: 10.1155/2014/502676

Sahlmann, C., Djordjevic, B., Lagos, L., and Mydland, L. T., Øverland, M. (2019). Yeast as a protein source during smoltification of Atlantic salmon (Salmo salar L.), enhances performance and modulates health. Aquaculture 513:734396. doi: 10.1016/j.aquaculture.2019.734396

Secombes, C. J., Wang, T., Hong, S., Peddie, S., Crampe, M., Laing, K. J., et al. (2001). Cytokines and innate immunity of fish. Dev. Comp. Immunol. 25, 713-723. doi: 10.1016/S0145-305X(01)00032-5

Shi, C. S., Shenderov, K., Huang, N. N., Kabat, J., Abu-Asab, M., Fitzgerald, K. A., et al. (2012). Activation of autophagy by inflammatory signals limits IL$1 \beta$ production by targeting ubiquitinated inflammasomes for destruction. Nat. Immunol. 13, 255-263 doi: 10.1038/ni.2215

Simpson, S., Allen, W. E., Conrado, R. J., and Molloy, S. (2016). Gas Fermentation for the Production of Protein or Feed. U.S. Patent No 0338380A1. Skokie, IL: U.S. Patent and LanzaTech, Inc.

Sitjà-Bobadilla, A., Pe?a-Llopis, S., Gómez-Requeni, P., Médale, F., Kaushik, S., and Pérez-Sánchez, J. (2005). Effect of fish meal replacement by plant protein sources on non-specific defence mechanisms and oxidative stress in gilthead sea bream (Sparus aurata). Aquaculture 249, 387-400. doi: 10.1016/j.aquaculture.2005.03.031

Sla, B., Min, D. A., Hq, A., and Nca, C. (2020). Effects of fishmeal replacement with composite mixture of shrimp hydrolysate and plant proteins on growth performance, feed utilization, and target of rapamycin pathway in largemouth bass, Micropterus salmoides. Aquaculture 533:736185. doi: $10.1016 /$ j.aquaculture. 2020.736185

Su, J. Z., Gong, Y. L., Cao, S. P., Lu, F., Han, D., Liu, H. K., et al. (2017). Effects of dietary Tenebrio molitor meal on the growth performance, immune response and disease resistance of yellow catfish (Pelteobagrus fulvidraco). Fish Shellfish Immunol. 69, 59-66. doi: 10.1016/j.fsi.2017.08.008

Su, M., Mei, Y., and Sinha, S. (2013). Role of the crosstalk between autophagy and apoptosis in cancer. J. Oncol. 2013:102735. doi: 10.1155/2013/102735

Sun, J. L., Zhao, L. L., Liao, L., Tang, X. H., Cui, C., Liu, Q., et al. (2020). Interactive effect of thermal and hypoxia on largemouth bass (Micropterus salmoides) gill and liver: aggravation of oxidative stress, inhibition of immunity and promotion of cell apoptosis. Fish Shellfish Immunol. 98, 923-936. doi: $10.1016 /$ j.fsi.2019.11.056

Utturkar, S. M., Klingeman, D. M., Bruno-Barcena, J. M., Chinn, M. S., Grunden, A. M., Kopke, M., et al. (2015). Sequence data for Clostridium autoethanogenum using three generations of sequencing technologies. Sci. Data. 2:150014. doi: $10.1038 /$ sdata.2015.14

Wang, W., Xu, Y., Chi, S., Yang, P., and Song, F. (2020). Dietary lysine regulates body growth performance via the nutrient-sensing signaling pathways in largemouth bass (Micropterus salmoides). Front. Mar. Sci. 7:595682. doi: $10.3389 /$ fmars.2020.595682
Wei, H., Huan, Y. U., Chen, X., Chao, W., Zou, F., Chen, P., et al. (2018). Effects of soybean meal replaced by Clostridium autoethanogenum protein on growth performance, plasma biochemical indexes and hepatopancreas and intestinal histopathology of grass carp (Ctenopharyngodon idllus). Chinese. J. Anim. Nutr. 30, 4190-4201.

Yang, P., Yang, W., He, M., Li, X., and Leng, X. (2020). Dietary synbiotics improved the growth, feed utilization and intestinal structure of largemouth bass (Micropterus salmoides) juvenile. Aquac. Nutr. 26, 590-600. doi: $10.1111 /$ anu. 13020

Yin, P., Xie, S. W., Zhuang, Z. X., He, X. S., Tang, X. P., Tian, L. X., et al. (2020). Dietary supplementation of bile acid attenuate adverse effects of high-fat diet on growth performance, antioxidant ability, lipid accumulation and intestinal health in juvenile largemouth bass (Micropterus salmoides). Aquaculture 531:735864. doi: 10.1016/j.aquaculture.2020.7 35864

Yu, H. H., Zhang, L. L., Chen, P., Liang, X. F., Cao, A. Z., Han, J., et al. (2019). Dietary bile acids enhance growth, and alleviate hepatic fibrosis induced by a high starch diet via AKT/FOXO1 and cAMP/AMPK/SREBP1 pathway in Micropterus salmoides. Front. Physiol. 10:1430. doi: 10.3389/fphys.2019. 01430

Zeng, J., Chen, Y., Ding, R., Feng, L., Fu, Z. H., Yang, S., et al. (2017). Isoliquiritigenin alleviates early brain injury after experimental intracerebral hemorrhage via suppressing ROS-and/or NF- $\kappa$ B-mediated NLRP3 inflammasome activation by promoting $\mathrm{Nrf2}$ antioxidant pathway. $J$. Neuroinflammation 14:119. doi: 10.1186/s12974-017-0895-5

Zhang, P. Y., Cao, S. P., Zou, T., Han, D., Liu, H. K., Jin, J. Y., et al. (2018). Effects of dietary yeast culture on growth performance, immune response and disease resistance of gibel carp (Carassius auratus gibelio CAS III). Fish Shellfish Immunol. 82, 400-407. doi: 10.1016/j.fsi.2018.08.044

Zhou, M., Liang, R., Mo, J., Yang, S., Gu, N., Wu, Z., et al. (2018). Effects of brewer's yeast hydrolysate on the growth performance and the intestinal bacterial diversity of largemouth bass (Micropterus salmoides). Aquaculture 484, 139-144. doi: 10.1016/j.aquaculture.2017.11.006

Conflict of Interest: The authors declare that the research was conducted in the absence of any commercial or financial relationships that could be construed as a potential conflict of interest.

Publisher's Note: All claims expressed in this article are solely those of the authors and do not necessarily represent those of their affiliated organizations, or those of the publisher, the editors and the reviewers. Any product that may be evaluated in this article, or claim that may be made by its manufacturer, is not guaranteed or endorsed by the publisher.

Copyright $\odot 2021 \mathrm{Lu}, \mathrm{Xi}$, Liu, Gong, Su, Han, Yang, Jin, Liu, Zhu and Xie. This is an open-access article distributed under the terms of the Creative Commons Attribution License (CC BY). The use, distribution or reproduction in other forums is permitted, provided the original author(s) and the copyright owner(s) are credited and that the original publication in this journal is cited, in accordance with accepted academic practice. No use, distribution or reproduction is permitted which does not comply with these terms. 